\title{
Prejuízos decorrentes de perdas na colheita do algodão com diferentes tipos de colhedoras
}

\author{
Leonardo Aparecido Inacio Leite ${ }^{1}$, Aldo Nuss ${ }^{1}$ \\ ${ }^{1}$ Faculdade La Salle, Unidade de Lucas do Rio Verde, Lucas do Rio Verde, Mato Grosso, Brasil. E-mail: inacioleite@gmail.com, \\ aldo@faculdadelasalle.edu.br
}

Recebido:17/05/2017; Aceito: 02/11/2017

\section{RESUMO}

Com o aumento da procura de algodão, surgiram novas técnicas de cultivo que reduzem o espaçamento entre linhas $(0,76 \mathrm{~m}$ e $0,45 \mathrm{~m})$, aumentando a densidade de plantas, diminuindo o ciclo da cultura e conduzindo à um consequente aumento de produção. Com as novas tecnologias associadas à fatores tais como climáticos, de topografia do solo, das variedades utilizadas e das regulagens e modelos de colhedoras, surgiram também os problemas com perda na colheita. O objetivo do trabalho foi mensurar e analisar a viabilidade econômica das perdas na colheita do algodão, com alguns modelos de colhedoras, verificando qual modelo oferece melhor rendimento para o espaçamento de $0,45 \mathrm{~m}$ entre linhas. A metodologia utilizada foi de estudo de campo, avaliando áreas colhidas por cada colhedora em uma jornada de trabalho. Os resultados obtidos para o rendimento operacional foram abaixo do desejado; as perdas foram superiores ao padrão estabelecido, podendo diminuir o valor com melhor regulagem das colhedoras. O modelo de colhedora que se destacou com menor perda foi a de Escova.

Palavras-chave: rendimento operacional, diferentes espaçamentos, aumento de produção.

\section{Losses due to losses in cotton harvesting with different types of harvesters}

\begin{abstract}
As cotton demand increased, new cropping techniques emerged, such as reducing line spacing, increasing plant density, decreasing crop cycle and increasing yield. New spacing of $0.76 \mathrm{~m}$ and $0.45 \mathrm{~m}$ between rows appeared. With the installation of new technologies, problems also arose, such as loss of harvest due to climatic factors, soil topography, varieties used and adjustments and models of harvesters. The objective of this study was to measure and analyze the economic viability of losses in the cotton harvest, with some models of harvesters, verifying which model has the best yield for the spacing of $0.45 \mathrm{~m}$ between rows. The methodology used was field study, evaluating areas harvested by each harvester in a working day. The results obtained for the operational performance were lower than the desired one, the losses were higher than the established standard, being able to decrease the value with the implantation of the $5 \mathrm{~W} 2 \mathrm{H}$ system and with adjustments of the harvesters, the model of harvester that stood out with less loss was the Brush.
\end{abstract}

Key words: operating income, different spacings, increase in production. 


\section{Introdução}

O cultivo de algodão (Gossypium L.) tem se apresentado relevante em todo mundo. Dispõe de vasta utilização; no beneficiamento separa a fibra do caroço fornecendo a fibra, o próprio algodão, para utilização têxtil e fiação utilizado nas industrias químicas e farmacêuticas; do caroço, depois de retirado o linter, (pequenas penugens que ficam presas no caroço), procede-se ao esmagamento de onde obtém-se óleos usados para alimentação; o farelo supre a produção de ração animal.

A produção vem se destacando nos grandes países produtores. No Brasil, vem aumentando sua produção, ocupando a sexta colocação entre os maiores produtores de algodão; a produção nacional abrange 1.396,0 mil hectares, sendo a região centro oeste a responsável por 62,8\% desta área (CONAB, 2012).

O Estado do Mato Grosso detêm o título de maior produtor de algodão do país, pioneiro nas implantações de novas tecnologias como a redução do espaçamento entre linhas cujo maior objetivo é a redução dos custos de produção, com menor número de atividades realizadas devido ao encurtamento do ciclo da cultura de 180 para 150 a 120 dias (SILVA et al., 2010; FERREIRA et al., 2013).

Com o surgimento destes espaçamentos as tecnologias mudaram assim como a ótica dos proprietários rurais. $\mathrm{O}$ cultivo do algodão tem sido realizado com espaçamentos de $0,76 \mathrm{~m}$ a $0,90 \mathrm{~m}$ entre linhas, semeado em dezembro. Outro espaçamento utilizado é de 0,45 m entre linhas, podendo ser cultivado em primeira e segunda safra, semeado em dezembro ou em janeiro, respectivamente (FERREIRA et al., 2013).

Existe a necessidade de se buscar alternativas de redução de espaçamento entre linhas, que melhor se desenvolvam em nosso país, tendo em vista fatores como a redução de custo de produção, diminuição das perdas na colheita, ponto de maturação da cultura, velocidade de deslocamento e regulagens das máquinas, modelo de colhedora e habilidade do operador (Ferreira et al., 2015).

Os modelos de colhedoras utilizados para colheita de algodão de espaçamento reduzido devem ter seu desempenho acompanhado durante a colheita a fim de verificar e corrigir erros visíveis durante o processo. Desta forma já se torna possível diminuir as perdas quantitativas bem como qualitativas (FERREIRA et al., 2013). A colheita deve ser realizada sem perdas para o produtor, no menor tempo possível. Demora na colheita, devido à fatores climáticos adversos podem acarretar em aumento de perdas (SILVA et al., 2007).

Este trabalho objetiva mensurar e analisar a viabilidade econômica das perdas na colheita do algodão, com alguns modelos de colhedoras, verificando qual modelo oferece o melhor rendimento.

\section{Material e Métodos}

Este estudo foi realizado com a coleta de informações por intermédio de profissionais envolvidos no processo de colheita de algodão. A lavoura avaliada neste estudo de campo foi no Grupo Pinesso, unidade situada no Distrito Parque Água Limpa, Nova Ubiratã, MT, cuja colheita foi realizada em uma área de 4.500 hectares com espaçamento de 0,45 m entre linhas.

Para realização da colheita foram utilizados quatro modelos de máquinas: com o modelo Stripper agregado com o sistema de pré limpeza (HL extrator) foram colhidos 800 hectares; sem a utilização do equipamento HL foram colhidos 1.700 hectares; a colhedora com o sistema de colheita tipo Escova colheu uma área de 1.100 hectares e a colhedora com o sistema de Corte colheu os 900 hectares restantes.

Os dados foram obtidos em pesquisa de campo, coletada uma amostra para cada 20 hectares. As amostras foram feitas com uma distância mínima de 300 metros da bordadura do talhão, em um ponto homogêneo, colhendo-se as plumas de 5 linhas por 2 metros de comprimento (Figura 1); após a coleta, as plumas foram acondicionadas em embalagens, devidamente identificadas e realizada a pesagem das amostras.

Com a divisão da área para cada modelo de colhedora, a quantidade de amostras teve uma variação em cada modelo analisado: quarenta amostras para o sistema Stripper com HL; 85 para o mesmo modelo mas sem o uso do HL; 55 amostras no modelo de Escova e 45 amostras para o modelo de corte.

As amostras foram retiradas em dois momentos no mesmo local. A primeira amostra avaliou a perda natural, coletada antes da entrada das máquinas no talhão. O segundo momento de avaliação foi após a colheita, neste momento coletaram-se as plumas ainda presas na parte aérea e plumas caídas no solo devido à colheita mecânica.

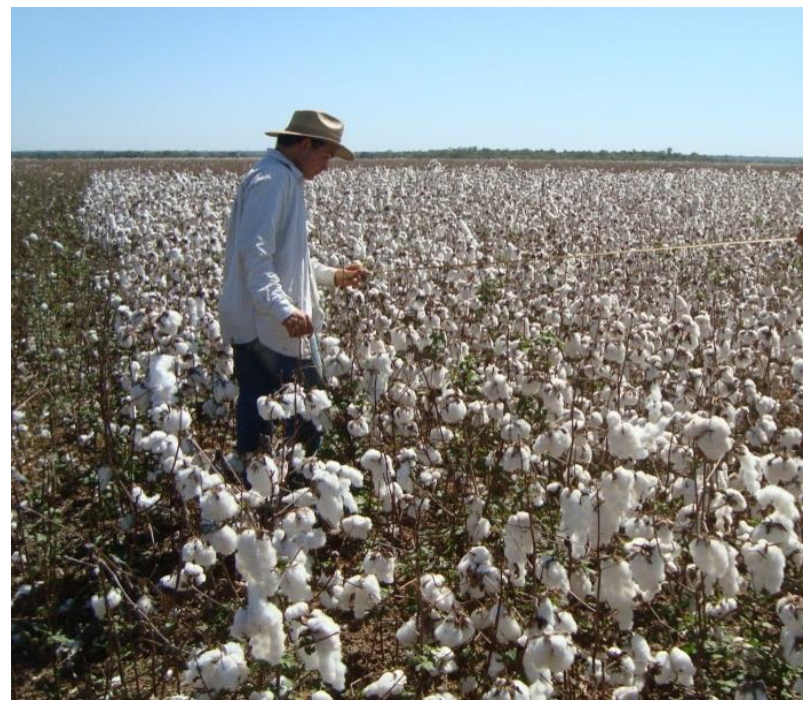

Figura 1. Demarcação da área para coleta de dados. 
A perda natural ocorre devido à maturação fisiológica da cultura, com o atraso das máquinas para colher, as plumas se soltam das brácteas e ficam no solo. Caso ocorra chuvas as plumas ainda fixas nas plantas podem cair aumentando a perda.

Após a colheita, plumas podem ficar retidas nas plantas, o que caracteriza perda na parte aérea. Podem ficar plumas caídas no solo, devido ao derrubamento e são classificados como perda mecânica ou perda terrestre.

Finda a colheita, foram realizadas duas análises de perdas restantes, plumas presas na parte aérea e plumas derrubadas pela colhedora (Figura 2). Novamente foi escolhido o ponto, e coletados separadamente os materiais do solo e da planta em uma parcela também de 5 linhas por $2 \mathrm{~m}$ de comprimento.

Depois da coleta das amostras de cada talhão e modelo de colhedora, realizou-se a pesagem e extrapolação de perdas por hectare. Após a pesagem das amostras, as mesmas foram armazenadas para futura verificação de peso.

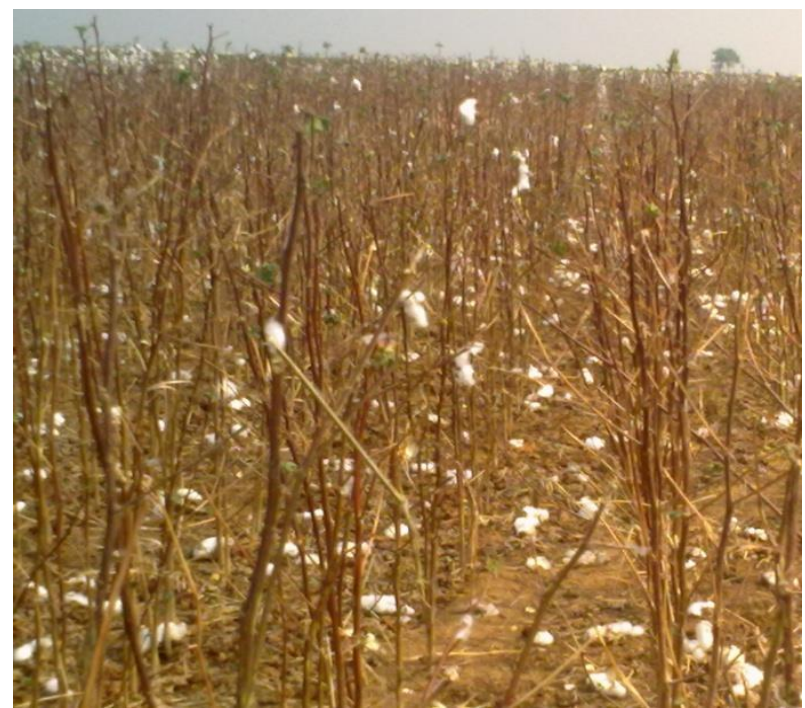

Figura 2. Plumas remanescentes no solo e plantas.

Com a obtenção dos pesos, calculou-se uma média de perda para cada talhão e cujos resultados estão apresentados em tabelas no decorrer do trabalho, separadas pelo modelo de colhedora. Para facilitar a interpretação dos dados, os mesmos serão apresentados, área em hectares (ha) e peso em arrobas (@).

Com a pesagem das amostras, foram analisados os valores de perdas na colheita, realizando um comparativo com este valor perdido no momento de colheita. O preço do mercado para algodão foi de R\$ 50,00/@ (Ferreira Filho et al., 2012).

Os valores foram comparados aos custos com a melhoria do quadro de funcionários, com a contratação de operadores e técnicos qualificados, comparando o valor do custo salarial livre para o funcionário sem os encargos. Para o comparativo de colaboradores foram realizados dois estudos, quantidade de pessoas em um único mês e também no decorrer de um ano.

Para se comparar os valores perdidos com investimentos que poderiam ser realizados na propriedade como a aquisição de equipamentos novos (colhedoras, pulverizadores) ou até mesmo com o pagamento de mão de obra qualificada, foram determinados e especificados os itens que serviram de meios para a comparação:

- Colhedoras de Algodão: R\$ 800.000,00 Representante John Deere, Sorriso - MT, 11/2012.

- Pulverizadores Autopropelidos com capacidade de 2.500 litros de calda: R\$ 500.000,00 - Representante Jacto, Sorriso - MT, 11/2012.

- Tratores com 430 cavalos vapor (cv) de potência: R\$ 480.000,00 - Representante Case, Sorriso - MT, $11 / 2012$.

- Óleo Diesel: R\$ 2,00/litro - Distribuidor de combustíveis de Sorriso - MT, 11/2012.

- Operador de Máquinas: R\$ 2.500,00 - Valor base pago pela propriedade, 11/2012.

- Técnico Agrícola: R\$3.000,00 - Valor base pago pela propriedade, 11/2012.

Outra avaliação realizada refere-se ao potencial de trabalho diário de cada máquina, especificado pelo fabricante e referente a cada modelo. Contudo, é perfeitamente possível que uma safra não consiga atingir este potencial devido à vários outros fatores. que podem diminuir o rendimento operacional de uma máquina tais como o não conhecimento do operador, condições climáticas adversas e topografia do terreno (FERREIRA et al, 2013).

No final de cada jornada de trabalho foi mensurada a área colhida por cada modelo de colhedora, com o auxilio de um aparelho de DGPS, em torno da área colhida; o valor foi registrado em planilha e calculadas as médias para servirem de comparativo com o rendimento potencial fornecido pelo fabricante de cada modelo de colhedora.

\section{Resultados e Discussão}

A propriedade em questão considera como perdas significativas as perdas acima de 3 arrobas por hectare. Desta forma, realizam-se frequentes ajustes na colhedora para que as perdas sejam inferiores a este limite.

No cultivo de $0,45 \mathrm{~m}$ entre linhas, para se obter melhor qualidade de pluma a velocidade de trabalho deve ser menor, no entanto o rendimento potencial das máquinas diminuem. Quando se trabalha com o sistema de pré limpeza no modelo Stripper, o rendimento é menor que $15 \mathrm{ha} /$ dia. As médias obtidas quando 
utilizado o HL Extrator foram de 3 ha/dia, trabalhando com $20 \%$ de seu rendimento potencial.

Quando se fez o isolamento do sistema de pré limpeza, o rendimento diário aumentou para 8 ha/dia, equivalente a $53,33 \%$ do rendimento potencial diário da máquina. Mesmo sem a utilização do HL o rendimento diário foi abaixo do informado pelo fabricante. Segundo o fabricante, a colhedora do tipo Escovas possui um rendimento potencial de $20 \mathrm{ha} / \mathrm{dia}$. No entanto, colhendo algodão com espaçamento de $0,45 \mathrm{~m}$ entre linhas a média obtida foi de $13 \mathrm{ha} / \mathrm{dia}$; valor $35 \%$ abaixo do rendimento esperado em condições favoráveis.

Outro modelo utilizado foi a colhedora de corte que possui um rendimento potencial de $15 \mathrm{ha} / \mathrm{dia}$; corta uma linha da cultura e envia as plantas para a unidade colhedora ao lado; a média obtida foi de $10 \mathrm{ha} /$ dia, apenas $66,63 \%$ do rendimento potencial. A ineficiência de $33,37 \%$ foi atribuída às condições climáticas e alinhamento das linhas de semeadura. As médias de valores das perdas natural, parte aérea e terrestre (plumas derrubadas pelas máquinas) estão apresentadas na Tabela 1. Os dados estão calculados em arrobas por hectare, especificando o modelo de colhedora e o espaçamento da cultura.

Tabela 1. Perdas de plumas na colheita do algodão

\begin{tabular}{lllll}
\hline $\begin{array}{l}\text { Modelo de } \\
\text { Colhedoras }\end{array}$ & $\begin{array}{l}\text { Perda } \\
\text { Natural } \\
\text { @ @/ha) }\end{array}$ & $\begin{array}{l}\text { Perda } \\
\text { Terrestre } \\
(@ / h a)\end{array}$ & $\begin{array}{l}\text { Perda } \\
\text { (@/ha) }\end{array}$ & $\begin{array}{l}\text { Perda } \\
\text { Total } \\
\text { (@/ha) }\end{array}$ \\
\hline Stripper com HL & 3,77 & 8,18 & 2,39 & 14,34 \\
Stripper sem HL & 4,64 & 7,11 & 2,30 & 14,05 \\
Escova & 0,90 & 5,27 & 4,74 & 10,91 \\
Corte & 1,29 & 6,72 & 3,80 & 11,81 \\
\hline
\end{tabular}

Valores obtidos através das amostragens realizadas.

As perdas são toleráveis em todas as culturas, desde que insignificantes à produção final. $\mathrm{O}$ valor aceitável de perda na colheita está entre 6 e $8 \%$, como apontado por Empaer/MT (1999). Neste estudo o tolerável limita a no máximo 3 @/há, equivalente a $2 \%$ de perdas, cuja média de produção na área total (4.500 hectares) foi de 150@/ha. Segundo Belot et al (2010), é possível obter uma colheita com a inexistência de perdas desde que se tenha condições normais de umidade da cultura, regulagens das máquinas e aperfeiçoamento, boas condições de topografia e bom treinamento do operador.

Com as avaliações realizadas, a maior perda obtida foi a terrestre em todos os modelos de colhedoras avaliadas. Corroborando com este resultado, Silva et al (2011) também observaram a maior perda na colheita da cultura com as plumas remanescentes no solo. As médias de perdas encontradas foram acima do valor permitido. Estes valores altos foram resultantes das condições da cultura e também da regulagem das máquinas, visto que cada modelo de colhedora tem suas próprias regulagens e mecanismo de colheita. (FERREIRA et al., 2013; FERREIRA et al., 2015).

A colhedora com o sistema de Escova obteve o menor valor de perda terrestre, mesmo sendo considerada uma máquina de bom desempenho. O valor obtido de $3,51 \%$ de perda foi acima da referência determinada, possivelmente pelo manejo adotado na área, onde a semeadura foi realizada sem uso de tratores equipados e com piloto automático, fato que prejudicou o alinhamento das linhas de cultivo e o bom desempenho da colhedora.

Para os outros modelos de colhedoras os problemas estão relacionados à regulagem das unidades de colheita que devem ter um melhor ajuste a fim de se evitar grandes perdas. A perda também pode estar relacionada à maturação da planta, pois no momento em que a unidade de colheita entra em contato com a planta, as plumas podem cair no solo.

O modelo de colhedora Stripper obteve o menor valor de perda na parte aérea das plantas, isto se deve à forma como a colhedora trabalha, como se penteando a cultura, evitando que fiquem plumas presas aos capulhos das plantas. $\mathrm{O}$ valor obtido de $1,6 \%$,foi menor que o valor de referencia. A colhedora de Escova apresentou valor de perda aérea alto devido à forma de colheita da máquina, como se escovasse a planta, podendo deixar alguma pluma sem ser retirada dos capulhos. A má regulagem da abertura da unidade de colheita da máquina também pode ter contribuído; devido à distância entre as partes, a planta teve livre passagem pelo centro sem ter suas plumas colhidas.

$\mathrm{Na}$ colhedora de corte observou-se valor de perda aérea pouco acima do permitido, justificável pelo sistema de colheita da máquina e pela altura da unidade de colheita em relação à altura das plumas deixando as mesmas sem serem colhidas próximo ao solo.

A colhedora que se destacou atingindo o menor índice de perda foi a Stripper sem HL Extrator. Este sistema de colheita perdeu 9,41@/ha, referente à soma da parte área e terrestre; valor acima da referencia adotada.

Com as tecnologias existentes no mercado a expectativa do produtor é que se alcance o mínimo de perda possível. O momento de colheita subentende que já foram realizadas todas as etapas de tratos culturais, onde foram investidos altos valores; a produção é a forma de retorno financeiro.

Considerando o valor da arroba de algodão de $\mathrm{R} \$$ 50,00 , os valores em reais que o produtor deixou de ganhar por hectare com as perdas ocorrentes na lavoura devido às falhas na colheita ou até mesmo às falhas relacionados à maturação da lavoura são demonstrados na Tabela 2 . 
Tabela 2. Estimativas dos prejuízos em reais por hectare, decorrente às perdas na colheita de algodão.

\begin{tabular}{lccccc}
\hline $\begin{array}{l}\text { Modelo de } \\
\text { Colhedoras }\end{array}$ & $\begin{array}{c}\text { Perda Total } \\
(@ / h a)\end{array}$ & $\begin{array}{c}\text { Perdas Permitidas } \\
(@ / h a)\end{array}$ & $\begin{array}{c}\text { Perdas Consideradas } \\
(@ / h a)\end{array}$ & $\begin{array}{c}\text { Preço doAlgodão } \\
(\mathrm{R} \$ / @)\end{array}$ & $\begin{array}{c}\text { Prejuízo } \\
(\mathrm{R} \$ / \mathrm{ha})\end{array}$ \\
\hline Stripper com HL & 14,34 & 3,00 & 11,34 & $\mathrm{R} \$ 50,00$ & $\mathrm{R} \$ 567,00$ \\
Stripper sem HL & 14,05 & 3,00 & 11,05 & $\mathrm{R} \$ 50,00$ & $\mathrm{R} \$ 552,50$ \\
Escova & 10,91 & 3,00 & 7,91 & $\mathrm{R} \$ 50,00$ & $\mathrm{R} \$ 395,50$ \\
Corte & 11,81 & 3,00 & 8,81 & $\mathrm{R} \$ 50,00$ & $\mathrm{R} \$ 440,50$ \\
\hline
\end{tabular}

Valores obtidos através das amostragens realizadas, calculado o prejuízo com base nas informações obtidas de preço (CEPEA/ESALQ, Outubro/2012).

No espaçamento de $0,45 \mathrm{~m}$ entre linhas as perdas são relacionadas com o modelo utilizado para a colheita da cultura. Para o modelo Stripper com o sistema de pré limpeza, a perda foi de 11,34 @/há, acima do valor permitido, deixando de ganhar $\mathrm{R} \$ 567,00$ por hectare. Com um faturamento médio por hectare de $\mathrm{R} \$ 7.500,00$, esta perda refere-se a $7,56 \%$ do faturamento. Com o mesmo modelo de colhedora sem a utilização do sistema de HL Extrator, a perda foi de 11,05@/ha acima do tolerável, deixando de ganhar $\mathrm{R} \$ 552,50 \mathrm{em}$ cada hectare, valor esse referente a 7,36\% do faturamento da lavoura por hectare.

O modelo de Escova teve uma perda de 7,91@/ha acima do valor permitido, com isto o produtor deixou de faturar 5,27\% a mais, deixando de ganhar $\mathrm{R} \$ 395,50$. No modelo de colhedora de corte observou-se perda acima do permitido; 8,81@/ha, perdendo $\mathrm{R} \$ 440,50$ por hectare, o equivalente à $5,87 \%$ do faturamento por hectare. Como a colheita de toda lavoura foi dividida por área entre os modelos de colhedoras, abaixo estão apresentados os prejuízos obtidos com as perdas referentes à cada modelo de colhedora e o total em reais que o produtor deixou de ganhar nesta safra. (Tabela 3)

A colhedora do tipo Stripper com o HL, equipamento de pré limpeza teve uma perda de 11,34@/ha, ou seja, R $\$ 453.600,00$, calculando-se a perda em toda a área colhida pela colhedora. O mesmo modelo de colhedora sem o sistema de HL instalado colheu uma área de 1.700 hectares de algodão, observando uma perda na colheita de 11,05@/ha ou $\mathrm{R} \$ 939.250,00$. A colhedora do tipo Escova colheu uma área de 1.100 ha de algodão, com perda de 7,91@/ha, representando $\mathrm{R} \$ 435.050,00$, sendo este o menor valor em comparação aos quatro modelos de colhedoras analisadas. A colhedora com sistema de corte colhendo uma área de 900 hectares revelou perda de 8,81@/ha ou um montante de $\mathrm{R} \$ 396.450,00$.

Tais prejuízos, se evitados poderiam ser revertidos em melhoria da estrutura da propriedade visando maior capacidade produtiva. (Tabela 4). Investindo o valor das perdas do modelo de colhedora Stripper com o HL Extrator em colhedoras, seria possível adquirir 0,56 máquinas por cada safra de algodão cultivado e 0,90 pulverizadores autopropelidos. Utilizando este valor de perda para adquirir tratores poderia se adquirir 0,94 (trator) por cada safra colhida de algodão e também adquirir 226.880 litros de óleo diesel. Para o mesmo modelo mas sem a utilização do sistema de pré limpeza (HL Extrator), o valor das perdas seria suficiente para adquirir 1,17 colhedora de algodão, 1,87 pulverizador autopropelido, 1,95 trator e para aquisição de 469.625 litros de óleo diesel.

Comparando o valor da perda seria suficiente para contratar 13,95 operadores qualificados no período de um ano, considerando 13 salários pagos. Para técnicos seria possível contratar 11,63 no período de um ano. Para colaboradores, poderiam ser contratados 28,9 operadores e 24,08 técnicos agrícolas pelo mesmo período.

No modelo de colhedora com o sistema de colheita escova, com o valor do prejuízo poderiam ser adquiridas 0,54 colhedora, 0,87 pulverizador autopropelido, 0,9 trator, 217.525 litros de óleo diesel. Na contratação de colabores o valor seria suficiente para 13,38 operadores e 11,15 técnicos durante um ano com 13 salários para cada. A colhedora que obteve o menor valor de prejuízo com as perdas na colheita foi o modelo com o sistema de corte mas ainda assim, com o valor da perda seria possível adquirir 0,49 colhedora, 0,79 pulverizador, 0,82 trator, 198.225 litros de óleo diesel, 12,19 operadores de máquinas e 10,16 técnicos agrícolas.

Com base nos dados da Tabela acima, no cultivo de 4.500 hectares de algodão, onde foi realizado o estudo, somando os valores de perda de todos os modelos analisados tem-se um montante de $\mathrm{R} \$ 2.224 .350,00 \mathrm{de}$ prejuízos na colheita dessa área. Sabendo-se que o valor de uma colhedora nova gira em torno de $\mathrm{R} \$ 800.000,00$ o montante serviria para aquisição de 2,78 máquinas novas, por cada safra sem perdas. Ao utilizar o mesmo valor pode-se adquirir 4,44 pulverizadores autopropelidos avaliados em $\mathrm{R} \$ 500.000,00$.

Utilizando este valor para aquisição de tratores de grande porte com $430 \mathrm{cv}$, seria suficiente para compra de 4,63 no valor de $\mathrm{R} \$ 480.000,00$ por cada safra de algodão realizada na área. Caso opte pela compra de óleo diesel, cotado a $\mathrm{R} \$ 2,00$, adquirir-se-ia um volume de 1.112.175 litros. 
Tabela 3. Valor total do prejuízo com a perda na colheita do algodão.

\begin{tabular}{|c|c|c|c|c|}
\hline $\begin{array}{l}\text { Modelo de } \\
\text { Colhedoras }\end{array}$ & $\begin{array}{l}\text { Área Colhida } \\
\text { (ha) }\end{array}$ & $\begin{array}{l}\text { Perda Consideradas } \\
\text { (@/ha) }\end{array}$ & $\begin{array}{c}\text { Preço do Algodão } \\
(\mathrm{R} \$ / @)\end{array}$ & $\begin{array}{l}\text { Perda Total } \\
\quad(\mathrm{R} \$)\end{array}$ \\
\hline Stripper com HL & 800 & 11,34 & $\mathrm{R} \$ 50,00$ & $\mathrm{R} \$ 453.600,00$ \\
\hline Stripper sem HL & 1.700 & 11,05 & $\mathrm{R} \$ 50,00$ & $\mathrm{R} \$ 939.250,00$ \\
\hline Escova & 1.100 & 07,91 & $\mathrm{R} \$ 50,00$ & $\mathrm{R} \$ 435.050,00$ \\
\hline Corte & 900 & 08,81 & $\mathrm{R} \$ 50,00$ & $\mathrm{R} \$ 396.450,00$ \\
\hline Total & 4.500 & -- & -- & $\mathrm{R} \$ 2.224 .350,00$ \\
\hline
\end{tabular}

Tabela 4. Somatória dos comparativos de prejuízo na colheita do algodão.

\begin{tabular}{|c|c|c|c|c|c|c|c|c|}
\hline \multirow{2}{*}{$\begin{array}{l}\text { Modelo de } \\
\text { Colhedoras }\end{array}$} & \multirow{2}{*}{$\begin{array}{l}\text { Hectares } \\
\text { Colhidos }\end{array}$} & \multirow[b]{2}{*}{ Perda em Reais } & \multicolumn{6}{|c|}{ Investimentos Possíveis com os Valores das Perdas } \\
\hline & & & $\begin{array}{l}\text { Colhedoras } \\
\text { (un.) }\end{array}$ & $\begin{array}{l}\text { Autopropelidos } \\
\text { (un.) }\end{array}$ & $\begin{array}{c}\text { Tratores } \\
\text { (un.) }\end{array}$ & $\begin{array}{c}\text { Óleo Diesel } \\
\text { (L) }\end{array}$ & $\begin{array}{l}\text { Operadores } \\
\text { por ano }\end{array}$ & $\begin{array}{c}\text { Técnicos } \\
\text { por ano }\end{array}$ \\
\hline $\begin{array}{l}\text { Stripper com } \\
\text { HL }\end{array}$ & 800 & $453.600,00$ & 0,56 & 0,90 & 0,94 & 226.800 & 13,95 & 11,63 \\
\hline $\begin{array}{l}\text { Stripper sem } \\
\text { HL }\end{array}$ & 1.700 & $939.250,00$ & 1,17 & 1,87 & 1,95 & 469.625 & 28,90 & 24,08 \\
\hline Escova & 1.100 & $435.050,00$ & 0,54 & 0,87 & 0,90 & 217.525 & 13,38 & 11,15 \\
\hline Corte & 900 & $396.450,00$ & 0,49 & 0,79 & 0,82 & 198.225 & 12.19 & 10,16 \\
\hline Total & 4.500 & $2.224 .350,00$ & 2,78 & 4,44 & 4,63 & 1.112 .175 & 68,44 & 57,03 \\
\hline
\end{tabular}

Valores base obtidos na região de Sorriso - MT, Out/2011.

Se este valor das perdas na colheita fosse investido em funcionários qualificados, tanto para o monitoramento do campo como para operação de máquinas, seria suficiente para manter 68,44 operadores durante um ano recebendo 13 salários no valor de $\mathrm{R} \$$ 2.500,00 mensal, ou ainda 57,03 técnicos agrícolas, com 13 pagamentos durante um ano de $\mathrm{R} \$ 3.000,00$ mensal.

\section{Conclusões}

O desempenho das colhedoras foi abaixo dos valores especificados pelo fabricante. A falta de qualificação dos operadores e as condições da cultura com alta presença de ramificações laterais e desuniformidade do talhão podem ter influenciado no desenvolvimento das máquinas.

As perdas naturais poderiam ser evitadas com a entrada no momento correto no talhão para realizar a colheita e também no controle de aplicação do desfolhante na cultura. Quanto às perdas terrestres e de parte aérea, o problema encontrado foi na regulagem das unidades colhedoras, que devem sofrer ajustes realizados em cada talhão, para que se evitem divergências entre talhões.

Quanto às perdas totais a colhedora que obteve menor valor de perda foi o modelo escova, e a de maior valor o modelo Stripper sem HL. Com base nestes dados aconselha-se o cultivo de algodão adensado, realizando a colheita com a colhedora de escova.

\section{Referências Bibliográficas}

BELOT, J. L.; RIBAS, P.; VILELA, P. Resultados do Cultivo Adensado em Grande Escala em Mato Grosso na Safra Agrícola 2009. In: BELOT, J. L.; VILELA, P. A.; JACOMAZI, D.; O Sistema do Cultivo do Algodoeiro Adensado em Mato Grosso: Embasamentos e Primeiros Resultados, Cuiabá- MT: Defanti, 2010, p. 375 - 390.

FERREIRA FILHO, J. B. S.; ALVES, L. R. A.; BRAGUETTA, M. A. N. S.; CORRÊA, A. L. INDICADOR DO ALGODÃO,CEPEA/ESALQ, Piracicaba. Disponível em: https://www.cepea.esalq.usp.br/br/indicador/algodao.aspx, Acesso em: 17 de dez. 2012.

CONAB. COMPANHIA NACIONAL DE ABASTECIMENTO. Acompanhamento da Safra Brasileira, Safra 2011/2012, Brasília-DF: CONAB, 2012. Disponível em: 〈http://www.conab.gov.br/>. Acesso em: 15 dez. 2012.

EMPAER/MT. EMPRESA MATO-GROSSENSE DE PESQUISA, ASSISTÊNCIA E EXTENSÃO RURAL/MATO GROSSO. Diretrizes Técnicas - Algodão. Cuiabá-MT: Região Cerrados, 1999. 48 p

FERREIRA, F. M.; FIORESE, D. A.; SILVA, A. R. B. Sistemas de Colheita PICKER E STRIPPER: Características e Influências da Colheita Mecanizada de Algodão Adensado no Estado de Mato Grosso, Enciclopédia Biosfera, Centro Cientifico Conhecer, Goiânia-GO, v. 9 n. 17, p. 2377, 2013.

FERREIRA, F. M.; KAZAMA, E. H.; FIORESE, D. A.; SILVA, A. R. B. Velocidade de Colheita Sobre as perdas Quantitativas e o Percentual de Fibra do Algodão, Enciclopédia Biosfera, Goiania-GO, v. 11, n. 21, p. 1923, 2015. 
SILVA, O. R. R. F.; SOFIATTI, V.; BELOT, J. L. Colheita do Algodão Adensado. In: BELOT, J-L.; VILELA, P. A.; JACOMAZI, D.; O Sistema do Cultivo do Algodoeiro Adensado em Mato Grosso: Embasamentos e Primeiros Resultados. Cuiabá-MT: Defanti, 2010, p. 293 - 310.

SILVA, R. P.; FERREIRA, I. C.; CASSIA, M. T. Perdas na Colheita Mecanizada de Algodão, Scientia Agropecuária, Trujillo, v. 2, n. 1, p. 7-12, 2011.
SILVA, R. P.; SOUZA, F. G.; CORTEZ, J. W.; FURLANI, C. E. A.; VIGNA, G. P. Variabilidade Espacial e Controle Estatístico do Processo de Perdas na Colheita Mecanizada do Algodoeiro. Revista de Engenharia Agrícola, JaboticabalSP, v. 27, n. 3, p. 742-752, 2007. 